\title{
As Famílias Pluriativas e Não Agrícolas no Rural Brasileiro: condicionantes e diferenciais de renda ${ }^{1}$
}

Camila Strobl Sakamoto ${ }^{2}$, Carlos Alves Nascimento ${ }^{3}$ e Alexandre Gori Maia ${ }^{4}$

Resumo: Frente à discussão em torno da renda proveniente de atividades não agrícolas e sua importância para a população rural brasileira, este artigo analisa (i) os condicionantes da pluriatividade e da condição não agrícola das famílias rurais e (ii) os impactos das atividades não agrícolas na renda das famílias rurais. As análises baseiam-se em dados empilhados da PNAD de 2001 a 2013, período caracterizado por marcantes transformações na economia e sociedade rural. Os resultados destacam como as chances de a família rural possuir atividade não agrícola dependem tanto de fatores endógenos à estrutura familiar, como a presença de filho em idade adulta e escolaridade da pessoa responsável, quanto de fatores exógenos, como a proximidade do domicílio às áreas urbanas e região geográfica. Apesar das sensíveis melhoras no emprego e renda agrícola nos anos 2000, manteve-se o ritmo histórico de redução das famílias com atividade exclusivamente agrícola no rural brasileiro. Essa dinâmica justificar-se-ia, em parte, pela renda das famílias com atividades não agrícola, que é maior que a das famílias exclusivamente agrícolas e apresentou crescimento superior no período, contribuindo para a intensificação das disparidades de renda no meio rural.

Palavras-chaves: Mercado de trabalho agrícola; Pluriatividade; Desigualdade; Renda agrícola; Demografia rural.

Abstract: Based on the discussion of the income from non-agricultural activities and its importance for the Brazilian rural population, this study analyzes: (i) the determinants of pluriactivity and non-agricultural activities in rural households; and (ii) the impact of non-agricultural activities in the income of rural households. Analyses are based on pooled data from the National Household Survey from 2001 to 2013, period that is characterized

1. Data de submissão: 14 de julho de 2015. Data de aceite: 15 de junho de 2016 .

2. Doutoranda da Universidade Estadual de Campinas. Campinas, São Paulo, Brasil. E-mail: camilasaka@uol.com.br

3. Professor da Universidade Federal de Uberlândia. Uberlândia, Minas Gerais, Brasil E-mail: carlos.nascimento@ufu.br

4. Professor da Universidade Estadual de Campinas. Campinas, São Paulo, Brasil. E-mail: gori@unicamp.br 
by remarkable changes in the economy and rural society. Results highlight that the odds of having a non agricultural activity depends both on endogenous characteristics, such as the presence of a son/daughter in adult age and education of the responsible for the household, as exogenous factors, such as the proximity of the household from urban areas and geographic region. Despite considerable improvements in employment and income from agricultural activities in the 2000s, the share of families performing exclusively agricultural activities remained reducing in rural Brazil. This dynamic would be justified, in part, by the income of non-agricultural activities, which is greater than that of exclusively agricultural families and grew faster in the period, contributing to the enhancement income disparities in rural areas.

Key-words: Agricultural labor market; Pluriactivity; Inequality; Agricultural income; Rural demography.

DOI - http://dx.doi.org/10.1590/1234-56781806-94790540309

Classificação JEL: J43, R11, R23.

\section{Introdução}

Em contraposição à tendência de redução das ocupações agrícolas no rural brasileiro, houve um aumento relevante da participação do trabalho não agrícola na população ocupada rural, especialmente durante as décadas de 1990 e 2000. Em termos de geração de renda, as ocupações não agrícolas passam a ter crescente importância na composição da renda familiar rural (MATTEI, 2007; NASCIMENTO, 2008; SILVA, 2010; SCHNEIDER et al., 2013; CARDOSO, 2013; entre outros).

O surgimento de novas atividades no próprio meio rural, a maior comunicação e integração com as áreas urbanas (com o aumento do acesso ao transporte público) contribuíram para o maior ingresso de trabalhadores rurais às atividades não agrícolas. De acordo com Silva (2010), as atividades desenvolvidas nos estabelecimentos agropecuários brasileiros estariam, cada vez mais, deixando de ser responsabilidade do conjunto de membros para ser de um ou poucos membros familiares (em geral, do pai e um dos filhos homens). Por outro lado, haveria uma tendência de aumento da participação em atividades não agrícolas dentre os integrantes dessas famílias.

As famílias rurais que conciliam, entre seus membros, atividades agrícolas e atividades não agrícolas (no interior ou fora de um determinado estabelecimento produtor), denominadas famílias pluriativas, encontram-se no centro das discussões contemporâneas sobre o desenvolvimento rural e, de forma mais ampla, o desenvolvimento de toda a sociedade (ORGANISATION FOR ECONOMIC CO-OPERATION AND DEVELOPMENT - OECD, 1998; BANCO INTERNACIONAL PARA RECONSTRUÇÃO E DESENVOLVIMENTO - BIRD, 2007; entre outros). Em geral, as atividades não agrícolas são relacionadas com maiores níveis de remuneração, na comparação com as atividades estritamente agrícolas (SCHNEIDER et al., 2013). Mesmo que os residentes rurais se insiram em ocupações de baixa qualificação, como no trabalho doméstico ou na construção civil (CAMPANHOLA e SILVA, 2000; NASCIMENTO, 2004).

A importância da atividade não agrícola na composição da renda domiciliar rural levanta importantes questões sobre os fatores que influenciam na condição de atividade da família (se agrícola, pluriativa ou não agrícola). São diversos os fatores que podem influenciar esta condição, sejam esses endógenos - como escolaridade e idade - ou exógenos à unidade familiar - estágio de desenvolvimento local, por exemplo (CHAYANOV, 1985; SCHNEIDER, 2003; CONTERATO, 2008; BALSADI, 2009; CARDOSO, 2013; entre outros).

Frente ao importante papel da atividade não agrícola na renda e na sociedade rural, este estudo tem como objetivos principais: (i) inves- 
tigar os condicionantes da condição de atividade das famílias rurais, mais especificamente dos fatores que interferem na propensão de uma família rural ser pluriativa ou não agrícola, e (ii) avaliar os impactos dessa condição de atividade familiar (agrícola, pluriativa e não agrícola) sobre a renda das famílias rurais brasileiras. Duas contribuições principais podem ser destacadas: (i) atualiza a discussão corrente da literatura sobre trabalho não agrícola no rural brasileiro, analisando a dinâmica entre 2001 e 2013, período caracterizado por expressivas transformações na sociedade e na economia rural; (ii) propõe novos métodos de avaliação da atividade não agrícola nos domicílios rurais, captando com mais precisão a evolução de seus determinantes e impactos sobre a renda domiciliar.

\section{Revisão da literatura}

\subsection{O contexto e impactos da pluriatividade no Brasil}

O tema da pluriatividade - particularmente das famílias rurais - é oriundo da realidade das economias e sociedades desenvolvidas, a exemplo da outrora Comunidade Econômica Europeia (CEE) - atualmente, e com maior número de países-integrantes, União Europeia. Quando essas sociedades passaram a conviver com problemas de crescentes taxas de desemprego urbano a partir dos anos 1970, seus formuladores de políticas públicas passaram a ver na pluriatividade uma via valorosa para conter o ritmo do êxodo rural-urbano, combater focos de pobreza rural e estabilizar as rendas familiares rurais - que do ponto de vista estritamente agrícola se mostravam muito voláteis. Todas essas funções atribuídas à pluriatividade seriam cruciais para melhorar as condições de reprodução social das famílias rurais, ao mesmo tempo que, ao mantê-las no rural, contribuíam para amenizar os problemas urbanos de desemprego (HILL, 1984; FULLER, 1990; TOLOSANA e PERSIVA, 1992; Comisión de las Comunidades Europeas - CCE, 1998).
Assim, os formuladores de políticas públicas para o rural da CEE revelavam sua compreensão de que cuidar da população rural - principalmente no que respeita às possibilidades múltiplas de ocupação e de geração de renda - implicaria também cuidar da população urbana. Ou seja, a resolução dos problemas urbanos estava também associada ao equacionamento das questões rurais, não só agrícolas, mas sobretudo agrárias, no sentido da promoção da ocupação da população rural nos diferentes setores da atividade econômica (particularmente não agrícolas), estimulando-as a permanecerem com residência no rural. Estudos promovidos pelo Banco Mundial desde a década de 1970 (por exemplo, ANDERSON e LEISERSON, 1978), já ressaltavam a importância de que o desenho das políticas de desenvolvimento rural deve também considerar o fomento às atividades não agrícolas. Nesse sentido, a OECD (1998) também reconheceu que a ocupação das famílias rurais em atividades não agrícolas é importante e que vinha crescendo ao longo do tempo na maioria dos países para os quais os dados estavam disponíveis. Por sua vez, o BIRD (2007) sustenta que "a prioridade da política [de desenvolvimento rural] é criar mais empregos, tanto na agricultura como na economia rural não agrícola" (p. 18).

$\mathrm{Na}$ esteira dessas pesquisas e constatações internacionais, a atividade não agrícola das famílias rurais, sobretudo a pluriatividade, passou também a ganhar destaque entre pesquisadores brasileiros a partir de meados dos anos 1990 . Alguns estudos sublinharam as características da pluriatividade em distintas regiões do país (por exemplo, SCHNEIDER, 2003; CONTERATO, 2008; PEREIRA, 2010; SCHNEIDER et al., 2013; ESCHER et al., 2014), enquanto outros se debruçaram sobre a perspectiva futura da pluriatividade também em diferentes regiões brasileiras (por exemplo, CAMPANHOLA e SILVA, 2000; NASCIMENTO, 2008; TEIXEIRA, 2009; CARDOSO, 2013).

Além das legitimidades da pluriatividade, baseadas nos pressupostos de estabilização das rendas rurais, combate à pobreza e contenção 
do êxodo rural, todos esses estudos registraram outras virtudes, como: ampliação da renda familiar; contribuição para maior dinamização das economias locais, em razão da maior integração dos mercados de trabalho agrícolas e não agrícolas; compreensão de que o meio rural não se circunscreve às atividades agropecuárias, mas que abarca múltiplas outras funções (como moradia, lazer, valorização ambiental, gastronômica, artesanal); contribuição para a segurança alimentar, particularmente das famílias rurais mais pobres, especialmente nos momentos de crises nos mercados de trabalho não agrícola, uma vez que se a pluriatividade preserva o vínculo das famílias a alguma atividade agropecuária (mesmo que não seja voltada para o mercado, mas, sobretudo, para o autoconsumo familiar).

Como decorrência dessas constatações sobre as potencialidades das atividades não agrícolas, passou-se a considerá-las importantes no fomento de políticas públicas voltadas para o desenvolvimento rural, que, por sua vez, podem ter implicações virtuosas também sobre o desenvolvimento urbano. Segundo Conterato (2008),

"o desenvolvimento rural passa cada vez mais a ser entendido como processo multissetorial, que envolve atividades agrícolas e não agrícolas, e multifuncional, porque cumpre, simultaneamente, funções produtivas, ambientais, ecológicas e sociais" (p. 137).

Não se pode, entretanto, afirmar que a pluriatividade, por si só, garanta a saída de uma família da situação de pobreza rural. Para que o efeito seja eficaz e sustentado, seria necessário que essa atividade não agrícola ocorresse em uma região relativamente desenvolvida, onde as condições de inserção no mercado não agrícola são mais favoráveis (NASCIMENTO, 2008; KAGEYAMA, 2008). Há um enorme diferencial, em termos qualitativos, dentro da pluriatividade que pode ser claramente caracterizado pelos extremos Sul e Nordeste brasileiro (CARDOSO, 2013; SCHNEIDER et al., 2013; NASCIMENTO, 2008).

\subsection{Definição e determinantes da pluriatividade}

Também é importante destacar as diferentes dimensões e abordagens que podem surgir na análise da pluriatividade. Como ressaltado por Schneider (2009), a definição da pluriatividade é bastante complexa e necessita, em estudo quantitativos, de determinado grau de arbitrariedade. A classificação pode ser dada, por exemplo, com base na informação do grande setor de atividade da pessoa ocupada (agropecuária e indústria, por exemplo), ou com base no tipo de processo produtivo em que o indivíduo está alocado dentro da cadeia de produção. Neste último caso, dentro do grande setor de atividade agrícola, existiriam ocupações estritamente agrícolas e eminentemente não agrícolas.

Dependendo do objetivo do estudo, a pluriatividade pode ainda ser investigada por diferentes unidades de análise. Sob a ótica da unidade produtiva, por exemplo, é possível analisar as relações da pluriatividade com o desenvolvimento da atividade agrícola e, mais especificamente, com a agricultura familiar. Também pode-se considerar o indivíduo como unidade de análise, para investigar, por exemplo, as características dos trabalhadores que exercem duas ou mais ocupações simultaneamente. Outra unidade de análise é o domicílio, que engloba diferentes tipos de famílias pluriativas. Neste caso, a pluriatividade se originaria de distintos comportamentos dos membros que constituem uma unidade familiar, ou seja, a pluriatividade estaria ligada a uma estratégia familiar (e não, necessariamente, produtora).

Mesmo com uma definição estabelecida, a pluriatividade pode se tornar bastante complexa. Considerando, por exemplo, a unidade domiciliar - unidade de análise do presente estudo -, a condição pluriativa pode englobar: tanto (i) famílias que se encontram em situação de extrema pobreza rural e buscam atividades fora da agricultura como forma de complementação da renda domiciliar (sendo que esses trabalhadores acabam usualmente se inserindo em ocupações 
de baixa qualificação e remuneração); quanto (ii) famílias que contam com a presença de membros altamente qualificados, com níveis de renda mais elevados, oriundas de uma interação mais dinâmica do rural-urbano e das atividades agrícolas com cadeias produtivas de atividades não agrícolas de maior valor agregado.

Aspecto relevante para a análise da pluriativade é, portanto, identificar seus principais determinantes e impactos sobre as condições de vida das pessoas. Destaque pode ser dado à análise dos determinantes endógenos à unidade familiar. Uma referência importante para esses estudos é a de Chayanov (1985), que faz uma análise demográfica da agricultura camponesa/familiar, de modo que as hipóteses comumente extraídas são: i) quanto maior o tamanho do contingente familiar (famílias extensas, ou seja, pai, mãe e filhos, e seus agregados, avós, tios etc.), maior a probabilidade de a família diversificar as fontes de trabalho e renda (tornar-se pluriativa); ii) à medida que se eleva a idade dos membros familiares, até um certo ponto, aumenta-se a possibilidade de a família diversificar as fontes de trabalho e renda (tornar-se pluriativa); iii) à medida que se elevam os anos de escolaridade dos membros familiares, até um certo ponto, aumenta a possibilidade de a família diversificar as fontes de trabalho e renda (tornar-se pluriativa). Ademais, a escolaridade é um fator importante para a inserção no mercado de trabalho não agrícola. A posse de um diploma de $1^{\mathrm{o}}$ grau ou, sobretudo, $2^{\circ}$ grau, é a chave para esta inserção, mesmo que em ocupações de baixa qualificação, como no caso do trabalho doméstico ou na construção civil (CAMPANHOLA e SILVA, 2000; NASCIMENTO, 2004).

As hipóteses descritas acima foram reafirmadas em estudos realizados por Schneider (2003), Conterato (2008), Balsadi (2009), Schneider et al. (2013). Entretanto, o estudo de Cardoso (2013), que analisa a evolução das famílias rurais (agrícolas, pluriativas e não agrícolas) das regiões Nordeste e Sul, revela que, embora exista maior aderência dessas características demográficas às famílias pluriativas, comparativamente às famílias agrícolas, essas características não conse- guem explicar a evolução no tempo do tamanho do contingente de famílias pluriativas. Por exemplo, a despeito da diminuição do tamanho médio do contingente de famílias pluriativas sulinas e do crescimento da média de anos de estudos e da idade de seus membros familiares entre 2002 a 2009, esse tipo familiar não exibiu uma trajetória nem de redução nem de crescimento, permanecendo estável ao longo do período analisado. Na década de 1990, com aqueles mesmos desempenhos nas respectivas variáveis demográficas, o número desse tipo familiar registrou decrescimento. Subentende-se daí que o declínio ou a estabilidade do conjunto das famílias pluriativas sulinas não foi influenciado por aquelas variáveis, embora lhes sejam características. Observações semelhantes foram feitas em relação às famílias pluriativas nordestinas.

O estudo de Cardoso (2013) foi realizado comparando as trajetórias dos contingentes familiares rurais (agrícolas, pluriativas e não agrícolas) com a evolução das respectivas variáveis sociodemográficas (tamanho, idade e escolaridade). Não houve, entretanto, um controle de outros fatores (exógenos e endógenos às unidades familiares) que permitisse uma acurada avaliação dos impactos dessas variáveis na determinação da pluriatividade em relação aos demais tipos de famílias.

Assim como a pluriatividade ganha importância no contexto de evolução de uma nova perspectiva de desenvolvimento rural, também se pressupõe que o desenvolvimento seja algo processual e, por conseguinte, dinâmico. Esta característica é ressaltada ao considerar os impactos das políticas públicas direcionadas à população rural e, particularmente, à agricultura familiar, que foram implementadas ao longo dos anos 2000. Como destacado por Nascimento (2008), essas políticas contribuíram para o desenvolvimento das atividades não agrícolas e da pluriatividade no meio rural brasileiro (especialmente em determinadas regióes). Outro exemplo da dinâmica existente na pluriatividade é o próprio efeito positivo gerado pela interação entre as atividades agrícolas e não agrícolas. Estudos apontam que, dentro de uma unidade produtora, a renda 
obtida em atividades não agrícolas pode reduzir restrições de acesso ao crédito agrícola, além de reduzir os riscos que envolvem o pagamento deste, contribuindo para o desenvolvimento das atividades agrícolas (LIMA e PIACENTI, 2009; JONASSON e HELFAND, 2010).

Assim, ao estudar a atividade não agrícola rural e a pluriatividade, seria ideal uma perspectiva de trajetória evolutiva (análise temporal), não estática (relacionado apenas às características próprias da pluriatividade, sem observá-las ao longo do tempo). Procurando suprir esta lacuna deixada pelos trabalhos anteriormente citados - os quais já registraram vários avanços nessa temática - este estudo seguirá a abordagem de autores como Cardoso (2013), Teixeira (2009), Nascimento (2008), Souza (2000), Sacco dos Anjos (2003), Mattei (1999), entre outros, que analisaram a pluriatividade em uma perspectiva temporal embora Cardoso (2013), entre esses, é que mais detidamente tenha se dedicado a tentar verificar alguma relação entre as variáveis sociodemográficas e a evolução das famílias pluriativas. Além de o presente estudo ampliar a análise dos fatores (endógenos) determinantes da atividade não agrícola rural para além do tamanho da família, idade e escolaridade da pessoa responsável, numa perspectiva temporal/evolutiva (numa série de tempo de 2001 a 2013), também considera outros importantes condicionantes exógenos, como a localização territorial, uma proxy do fator "entorno rural", e a região de residência, uma proxy para o estágio de desenvolvimento socioeconômico local.

\section{Material e métodos}

Para analisar os condicionantes da participação em atividades não agrícolas e a dinâmica da renda das famílias rurais, foram utilizados os dados da Pesquisa Nacional por Amostra de Domicílios (PNAD), fornecidos pelo Instituto Brasileiro de Geografia e Estatística (IBGE), de 2001 a 2013. É importante destacar que as PNADs de 2001 a 2003 não continham informações das áreas rurais dos estados de Rondônia, Acre, Amazonas, Roraima,
Pará e Amapá. Para viabilizar uma comparação no período analisado foram excluídas as pessoas com residência nestes estados.

Foram selecionadas as famílias extensas ocupadas (domicílios com pelo menos um integrante ocupado em alguma atividade econômica, remunerada ou não remunerada $)^{5}$ residentes das áreas rurais. Para melhor caracterização de uma família extensa, foram excluídos da amostra os residentes domiciliares na posição de empregado doméstico, parente de empregados domésticos e as pessoas que viviam no domicílio em regime de pensionato. Conforme Mattei (2007), essa eliminação segue a metodologia da maioria dos estudos brasileiros que quantificam a pluriatividade. A família deve ser considerada como locus onde as decisões são tomadas de forma conjunta, representando uma organização que toma decisões de forma estratégica frente às condições macrossociais. Neste sentido, devemos entender que a alocação de membros familiares no mercado de trabalho faz parte de uma estratégia familiar frente aos constrangimentos enfrentados pelas unidades familiares (SCHNEIDER, 2003; MATTEI, 2007).

São famílias pluriativas aquelas que contém pelo menos um membro ocupado em atividade agrícola e pelo menos um membro ocupado em atividade não agrícola. Define-se uma família agrícola aquela em que todos os membros ocupados são agrícolas (remunerados ou não remunerados) e família não agrícola aquela em que todos os integrantes ocupados trabalham em atividades fora da agricultura (independente da área censitária do empreendimento empregador). Para a definição da atividade do ocupado (agrícola ou não agrícola), considerou-se o grupo de atividade econômica do trabalho principal do integrante familiar (desconsiderando o tipo de ocupação e os trabalhos secundários dos ocupados). Ou seja, não foram consideradas definições mais específi-

5. Em 2001, havia 482 mil domicílios sem nenhum membro ocupado e, em 2013, havia 1.085 mil domicílios na mesma situação. Esse tipo domiciliar não foi considerado no estudo. As análises se baseiam em um total de 6.575 mil domicílios em 2001 e 7.154 mil domicílios em 2013. 
cas de pluriatividade, como aquelas propostas por Schneider (2009), que englobam diferentes tipos de segmentos de atividade e considera as especificidades das ocupações exercidas. ${ }^{6}$ Deve-se, entretanto, destacar que o presente estudo busca avaliar a eficácia da pluriatividade como estratégia familiar de fuga à pobreza e não como estratégia de reprodução da agricultura familiar. Esta última análise exigiria a utilização de outra unidade de análise, mais aproximada às atividades exercidas pelos trabalhadores rurais dentro de um mesmo estabelecimento familiar.

Dois modelos serão desenvolvidos para identificar os condicionantes das ocupações não agrícolas nas famílias rurais e investigar a dinâmica da renda domiciliar rural. Ambos são aplicados com dados das PNADs empilhados e ponderados pelo fator de expansão da amostra de cada ano.

\subsection{Propensão à pluriatividade e à condição não agrícola}

Para analisar os determinantes de uma família pertencer à categoria pluriativa ou não agrícola, estabeleceu-se uma relação logística multinomial entre a probabilidade de um domicílio ser pluriativo, não agrícola ou agrícola, com fatores associados a esta condição. Essa relação se baseia na função de probabilidade logística especificado por (PINDYCK e RUBINFELD, 2004):

$$
\ln \left(P_{h i} / P_{3 i}\right)=\theta_{h 0}+\sum_{j=1}^{k} \theta_{h 0} X_{j i}+\delta_{h} t+u_{h i}
$$

Em que $P_{n i}$ é a probabilidade da $i$-ésima família ser da categoria $h(h=1$ para pluriativo ou 2 para não agrícola). A categoria 3 (agrícola) é utilizada como referência de análise. Assim, a variável dependente, denominada logit, é o logaritmo natural da razão entre a probabilidade de a famí-

6. Schneider (2009) propõe uma tipologia da pluriatividade que contempla uma diversidade de formas assumidas pelas famílias pluriativas derivadas dos seus distintos determinantes (internos à unidade familiar, assim como também os associados ao contexto externo, tal como mercado de trabalho etc). A tipologia proposta consiste dos seguintes tipos de pluriatividade: pluriatividade tradicional ou camponesa; pluriatividade intersetorial; pluriatividade de base agrária; pluriatividade para-agrícola. lia pertencer ao tipo pluriativa $(h=1)$ ou não agrícola $(h=2)$ e a probabilidade de a família ser agrícola $(h=3)$. Em outras palavras, expressa quantas vezes a chance de a família ser pluriativa ou não agrícola é maior que a chance de ser agrícola (também chamada de odds). A variável $X_{j}$ é o $j$-ésimo determinante do tipo familiar, $t$ o ano da informação ( $t=1$ para 2001) e $u_{n}$ o erro não controlado pelo modelo. O coeficiente $\theta_{h 0}$ é o intercepto da equação para o $h$-ésimo logit, $\theta_{h j}$ o impacto do regressor $X_{j}$ e $\delta_{h}$ a variação anual no respectivo logit. Para obter o odds ratio, a relação direta entre a variação unitária de $X_{j}($ ou $t)$ e a variação no odds, deve-se calcular o antilogaritmo de $\theta_{h j}$ (ou $\left.\partial_{h}\right)$, ou seja, calcular $e^{\theta h j}\left(\right.$ ou $\left.e^{\theta h}\right)$.

Como determinantes da condição pluriativa ou não agrícola $\left(X_{j}\right)$ da família foram investigadas 24 variáveis:

a) duas variáveis binárias para distinguir três localidades rurais: i) aglomerado rural de extensão urbana; ii) aglomerado rural isolado e povoado; iii) áreas rurais isoladas e não povoadas (esta, considerada como categoria de referência ${ }^{7}$;

7. A categoria de áreas isoladas e não povoadas inclui três distintas descrições de áreas rurais oferecidas pela PNAD, são elas: aglomerado rural, isolado, núcleo; aglomerado rural, isolado, outros aglomerados; e zona rural exclusive aglomerado rural. Para esclarecimento, de acordo com Concla/ IBGE (2015), aglomerado rural é o nome dado a uma localidade situada em áreas não definidas legalmente como urbana e caracterizada por um conjunto de edificações permanentes e adjacentes, formando área continuamente construída, com arruamentos reconhecíveis e dispostos ao longo de uma via de comunicação. Extensão urbana é a localidade que está localizada a menos de um quilometro de distância das áreas urbanas de uma Cidade ou Vila, ou seja, constitui simples extensão da área urbana legalmente definida. Isolado é a que está localizada a uma distância igual ou superior a um quilômetro da área urbana de uma Cidade, Vila ou de um aglomerado rural já definido como de extensão urbana. Povoado, a localidade que possui pelo menos um estabelecimento comercial de bens de consumo frequentes e dois dos seguintes serviços ou equipamentos: um estabelecimento de ensino de $1^{\circ}$ grau em funcionamento regular, um posto de saúde com atendimento regular e um templo religioso de qualquer credo. Essa localidade corresponde a um aglomerado sem caráter privado ou empresarial ou que não está vinculado a um único proprietário do solo. Por fim, núcleo é a localidade que possui caráter privado ou empresarial, estando vinculado a um único proprietário do solo (empresas agrícolas, usinas etc.). 
b) cinco variáveis binárias para distinguir seis regiões: Norte, Nordeste (referência), Centro-Oeste, Sudeste (exceto o estado de São Paulo), estado de São Paulo e Sul. O estado de São Paulo foi discriminado isoladamente para considerar sua particular representatividade no território e na economia nacional;

c) duas variáveis binárias para distinguir três características de posição na ocupação de uma família: Empregadora, se a família conta com pelo menos um integrante ocupado na posição de empregador; Conta-Própria (referência de análise), se conta com pelo menos um integrante ocupado na posição de trabalhador por conta-própria e nenhum integrante na posição de empregador; Empregada, aquelas que contam com todos os integrantes que estavam ocupados na posição de empregado e nenhum integrante ocupado na posição de empregador ou conta-própria;

d) logaritmo da renda per capita agrícola (considerada a somatória das rendas provenientes do trabalho estritamente agrícola do domicílio dividido pelo número total de pessoa no mesmo domicílio);

e) uma variável binária para discriminar as famílias que contam com a presença de pelo menos um filho jovem em idade ativa, entre 15 e 24 anos (considerando as famílias sem filho jovem como referência);

f) uma variável binária para discriminar as famílias que contam com a presença de pelo menos um filho em idade adulta, 25 anos ou mais (considerando as famílias sem filho adulto como referência);

g) uma variável binária para discriminar famílias que contam com a presença de cônjuge em idade economicamente ativa, 15 anos ou mais (considerando as famílias sem cônjuge em idade ativa como referência);

h) uma variável binária para discriminar as famílias com a presença de aposentado(s) (considerando as famílias sem aposentados como referência);

i) cinco variáveis binárias para distinguir seis faixas etárias da idade das pessoas de referência no domicílio: 19 anos ou menos (referência); 20 a 29 anos; 30 a 39 anos; 40 a 49 anos; 50 a 59 anos; 60 anos ou mais;

j) uma variável binária que define o sexo da pessoa de referência no domicílio (considerando o sexo masculino como referência);

k) uma variável binária que define a cor ou raça da pessoa de referência no domicílio (considerando as pessoas cor ou raça branca e amarela como referência para comparação com os indivíduos de cor ou raça preta, parda e indígena);

1) três binárias para distinguir quatro grupos de escolaridade da pessoa de referência: i) sem escolaridade (categoria de referência); ii) primeiro grau incompleto (de $1 \mathrm{a}$ 4 anos de escolaridade); iii) primeiro grau completo e segundo grau incompleto (de 5 a 8 anos de escolaridade); e iv) segundo grau completo ou escolaridade maior (de 9 anos ou mais de escolaridade).

Para controlar uma eventual quebra estrutural causada pela mudança na definição das áreas rurais que ocorre após o período censitário, entre 2009 e 2011, foi também considerada uma variável binária que distingue as duas décadas de análise (anos 2000 como referência).

\subsection{Determinantes da renda domiciliar e dinâmica dos diferenciais}

Para investigar os diferencias de renda domiciliar total (RDT) das famílias rurais, foi ajustado um modelo com dados empilhados que considera mudanças estruturais no tempo. Em outras palavras:

$Y_{i}=\beta_{0}+\sum_{j=1}^{k} \beta_{j} X_{j i}+\sum_{j=1}^{2} \rho_{j} H_{j i}+\delta t+\sum_{j=1}^{2} \gamma_{j} H_{j i} \times t+e_{i}$

Em que a variável dependente $Y$ é o logaritmo natural da somatória da renda domiciliar prove- 
niente de todas as fontes e $H_{j}$ é a j-ésima binária ( $j=1$ ou 2 ) que discrimina o tipo familiar ( $j$ é 1 para pluriativa, 2 para não agrícola, e a categoria agrícola é a referência de análise). O coeficiente $\beta_{0}$ é o intercepto da equação; $\beta_{j}$ é o impacto do regressor $X_{j}$ e $\delta$ a variação anual em $Y$. Os coeficientes $y_{j}$ reprentam mudanças anuais nos impactos do tipo familiar $H_{j}$ sobre o logaritmo da renda. Como se trata de uma equação com regressando em forma logarítmica, os coeficientes representam variações relativas na renda domiciliar. Quando o regressor for uma variável binária, a variação relativa na renda familiar em relação à categoria de referência será dada por $e^{\beta}-1$ (HALVORSEN e PALMQUIST, 1980).

Em adição às variáveis independentes $X_{j}$ previamente descritas, foram considerados os seguintes regressores:

m) duas variáveis binárias para distinguir três tipos de família Pluriativa, Não Agrícola e Agrícola (esta última definida como categoria de base);

n) número de pessoas com renda positiva dentro do domicílio (proveniente de qualquer fonte de renda).

\section{Resultados}

\subsection{Características das famílias agrícolas, pluriativas e não agrícolas}

Segundo dados da PNAD, entre 2001 e 2013 houve um acréscimo de 580 mil domicílios rurais ocupados (com pelo menos uma pessoa ocupada no mercado de trabalho), enquanto o número total de residentes desses domicílios apresentou uma redução considerável de 2,3 milhões de pessoas. Isso reflete a redução do tamanho médio das famílias rurais, que passou de 4,1 para 3,4 membros por domicílio. Parte desse fenômeno é explicado por fatores demográficos, como o envelhecimento da população rural e a queda da fecundidade que, somada à atratividade das áreas urbanas, têm caracterizado o fenômeno de esvaziamento demográfico rural desde a década de 1960 (CAMARANO e ABRAMOVAY, 1999; MAIA, 2014). Estudos recentes apontam que, apesar das melhoras recentes, parcela majoritária dos trabalhadores agrícolas ainda apresentam precárias condições de trabalho, baixos rendimentos, elevada informalidade e baixa qualificação (MIRANDA e TIBURCIO, 2012; BUAINAIN et al., 2014).

Ao analisar mais atentamente as mudanças dentre os domicílios rurais ocupados, ressalta-se a redução da participação das famílias Agrícolas (Figura 1), apesar de este tipo familiar ainda representar a maior parcela dos domicílios e residentes rurais, cerca de $55 \%$ do total de domicílios rurais ocupados (ou quase 4 milhões de domicílios, que somavam 12,8 milhões de pessoas em 2013). A redução da participação deste tipo familiar teve início em 2004. Nos anos anteriores (entre 2001 e 2003), o auge do desempenho do setor agrícola permitiu que as ocupações agrícolas apresentassem sensível aumento do número total de ocupados, revertendo a tendência de forte queda absoluta observada na década de 1990 (MAIA e SAKAMOTO, 2014). É importante também destacar que o sensível aumento relativo das famílias agrícolas observado em 2011 está, provavelmente, associado às alterações metodológicas implementadas na delimitação de espaço rural da PNAD, realizada após o Censo de 2010. Embora a tendência de queda se mantivesse nos anos seguintes.

As famílias Não Agrícolas apresentaram o crescimento mais expressivo no período $683 \mathrm{mil}$ domicílios (chegando a responder por $26,5 \%$ do total de domicílios rurais ocupados em 2013, o que significa um crescimento de 8 pontos percentuais). O tipo de família Pluriativa também contou com acréscimo absoluto, embora menos expressivo, de 170 mil domicílios (passando a responder por $18,3 \%$ dos domicílios rurais brasileiros em 2013, crescimento de 1 ponto percentual). A menor participação deste tipo familiar ocorreu em 2003, exatamente no auge do período de maior crescimento da atividade agrícola brasileira. Ou seja, a pluriatividade seria provavelmente sensível às condições da atividade econômica da agricultura e, logo, à demanda por mão de obra nas atividades agrícolas. 
Figura 1. Participação de domicílios rurais $(\%)$ e renda domiciliar total média $\left(\mathrm{R} \${ }^{*}\right)$ segundo tipo familiar (agrícola, pluriativo e não agrícola). Brasil, 2001 a 2013
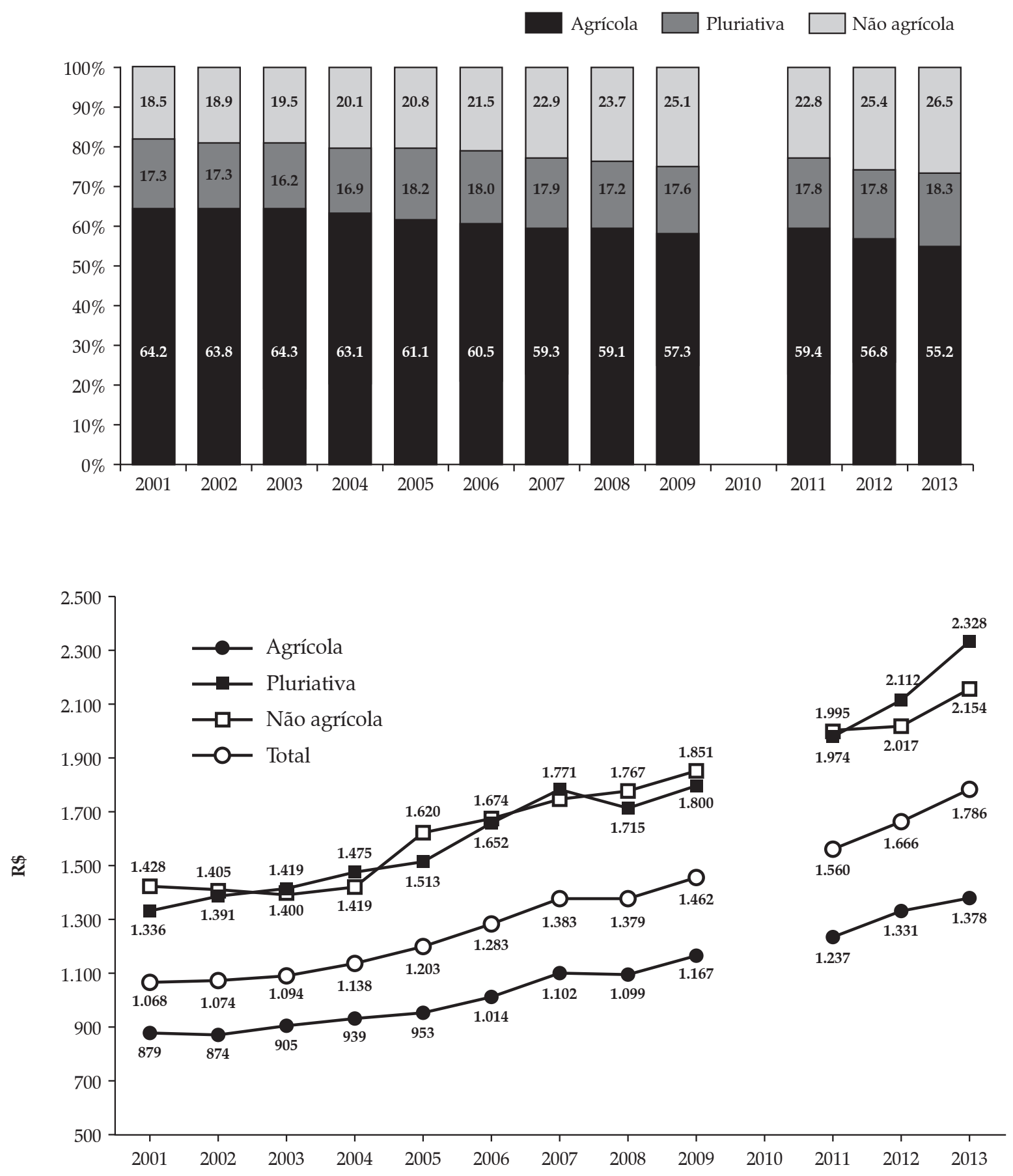

Exclusive os domicílios com nenhum membro ocupado. Exclusive os residentes da região Norte (exceto Tocantins).

* Valores deflacionados para outubro de 2013 segundo o INPC para a PNAD (CORSEUIL e FOGUEL, 2002).

Fonte: PNAD/IBGE. 
O crescimento da participação de famílias Não Agrícolas e Pluriativas justificar-se-ia pelos retornos econômicos do exercício da atividade não agrícola, uma vez que a renda dessas famílias é substancialmente superior à das famílias Agrícolas. Todos os grupos familiares apresentaram crescimento expressivo da RDT média no período, sobretudo as famílias Pluriativas $(74 \%$ entre 2001 e 2013). No geral, as disparidades de renda entre os tipos familiares permaneciam extremamente elevadas em 2013: a renda das famílias Pluriativas era $69 \%$ superior ao das famílias Agrícolas, e a renda das famílias Não agrícolas era $56 \%$ superior.

Diversas características socioeconômicas ajudam a explicar os diferenciais de RDT entre as famílias Pluriativas, Não Agrícolas e Agrícolas (Tabela 1). Em primeiro lugar, é importante destacar a posição da ocupação da família. As famílias Agrícolas se dividem majoritariamente em Conta-própria (44\% em 2013) e Empregada (55\%), tipos familiares com rendimentos médios inferiores ao das famílias do tipo Empregadora. Já as famílias Pluriativas se destacam pela maior concentração relativa nos grupos de família Empregadora e Conta-própria, o primeiro tipo caracterizado pelo maior rendimento médio entre os tipos familiares. Por sua vez, as famílias Não Agrícolas se caracterizam pela concentração do tipo familiar Empregada (65\% das famílias, onde todos os ocupados estão na posição de empregado). Apesar de esse tipo familiar estar associado a menores níveis de renda, as famílias Não Agrícolas Empregada apresentam renda substancialmente elevadas na comparação com as famílias Agrícolas nessa posição ocupacional, uma vez que desempenham atividades não agrícolas.

A presença de filho, sobretudo jovem, no domicílio é outra característica fortemente associada à pluriatividade. Em 2013, quase metade (47\%) das famílias Pluriativas tinham pelo menos um filho entre 15 e 24 anos, e praticamente um quarto dessas famílias (23\%) tinha pelo menos um jovem adulto (25 anos ou mais) residindo no domicílio. As famílias Pluriativas também se caracterizam pela presença de um cônjuge em idade ativa (80\% das famílias Pluriativas, contra $62 \%$ das famílias Agrícolas e $68 \%$ das Não Agrícolas). Entretanto, apesar de essas famílias terem maior oferta de mão de obra no domicílio, a renda dessas famílias é, em média, inferior à das famílias sem cônjuge em idade ativa, o que pode estar associado às formas mais vulneráveis de inserção das mulheres no mercado de trabalho.

O exercício da atividade exclusivamente agrícola está fortemente associado à presença de um aposentado no domicílio. O percentual de famílias Agrícolas com aposentados cresceu de 30\% em 2001 para 35\% em 2013 (contra 26\% das famílias Pluriativas e 16\% das Não Agrícolas em 2013). Uma possível justificativa para esta associação seria a idade média mais avançada das famílias Agrícolas. Cerca de 30\% das famílias Agrícolas eram chefiadas por pessoas de 60 anos ou mais em 2013 (contra 21\% das famílias Pluriativas e 14\% das famílias Não Agrícolas). Já os responsáveis pelas famílias Pluriativas concentravam-se na faixa etária entre 40 e 59 anos (53\%), e os das famílias Não Agrícolas entre 30 e 49 anos (52\%). Destaca-se também o fato de o rendimento domiciliar ser substancialmente superior para as famílias chefiadas por pessoas com idade mais avançada e, sobretudo, com aposentados no domicílio. Fato que estaria provavelmente associado à experiência profissional da pessoa responsável e à vinculação do pagamento das aposentadorias rurais ao salário mínimo, que se valorizou substancialmente no período.

A atividade não agrícola também se associa à localização espacial dos domicílios rurais. Enquanto as famílias Agrícolas e Pluriativas se concentravam quase que exclusivamente em áreas não povoadas e aglomerados isolados e povoados em 2013, 12\% das famílias Não Agrícolas residiam em áreas de extensão urbana, onde a renda domiciliar média é maior. A atividade não agrícola também está associada à região geográfica. Mais de metade das famílias Agrícolas e Pluriativas se concentravam no Nordeste. Embora parcela majoritária das famílias Não Agrícolas também se concentre nesta região (48\% em 2013), havia uma parcela relativamente elevada de domicílios na 
Tabela 1. Participação dos domicílios (\%) e renda domiciliar total (RDT em R\$) por características domiciliares e das pessoas de referência, segundo grupo de atividade econômica da família. Brasil, 2001 e 2013

\begin{tabular}{|c|c|c|c|c|c|c|c|c|c|c|c|c|c|}
\hline & \multirow{3}{*}{ Características } & \multicolumn{6}{|c|}{2001} & \multicolumn{6}{|c|}{2013} \\
\hline & & \multicolumn{2}{|c|}{ Agrícola } & \multicolumn{2}{|c|}{ Pluriativa } & \multicolumn{2}{|c|}{ Não agrícola } & \multicolumn{2}{|c|}{ Agrícola } & \multicolumn{2}{|c|}{ Pluriativa } & \multicolumn{2}{|c|}{ Não agrícola } \\
\hline & & $\%$ & $R D T^{*}$ & $\%$ & $R D T^{*}$ & $\%$ & $R D T^{*}$ & $\%$ & RDT & $\%$ & $R D T$ & $\%$ & RDT \\
\hline \multirow{3}{*}{$\begin{array}{l}\text { Posição de } \\
\text { ocupação }\end{array}$} & Empregadora & 4,9 & 2.967 & 7,1 & 3.117 & 4,6 & 4.092 & 1,8 & 5.625 & 3,8 & 7.759 & 3,4 & 5.902 \\
\hline & Conta-própria & 54,5 & 861 & 58,1 & 1.273 & 31,4 & 1.460 & 43,6 & 1.662 & 50,5 & 2.303 & 31,7 & 2.235 \\
\hline & Empregada & 40,5 & 673 & 34,8 & 1.100 & 64,0 & 1.217 & 54,5 & 1.024 & 45,8 & 1.879 & 64,9 & 1.899 \\
\hline \multirow{3}{*}{$\begin{array}{l}\text { Tipo da } \\
\text { localidade }\end{array}$} & Extensão urbana & 0,1 & 1.077 & 0,8 & 782 & 14,4 & 1.469 & 0,2 & 1.295 & 0,4 & 2.431 & 12,0 & 2.431 \\
\hline & Aglom. isolado e povoado & 5,3 & 628 & 9,5 & 1.024 & 17,2 & 1.369 & 10,7 & 987 & 15,5 & 1.682 & 19,4 & 1.686 \\
\hline & Áreas não povoadas & 94,7 & 893 & 89,7 & 1.374 & 68,4 & 1.435 & 89,1 & 1.431 & 84,2 & 2.449 & 68,5 & 2.238 \\
\hline \multirow{5}{*}{ Região } & Nordeste (mais TO) & 51,7 & 636 & 53,1 & 1.011 & 37,6 & 1.027 & 54,4 & 995 & 54,3 & 1.655 & 47,8 & 1.586 \\
\hline & Centro-Oeste & 6,9 & 1.033 & 7,0 & 1.547 & 7,0 & 1.699 & 6,7 & 1.901 & 7,2 & 2.577 & 5,9 & 2.691 \\
\hline & Sudeste (exceto SP) & 16,9 & 974 & 15,5 & 1.404 & 14,0 & 1.448 & 18,1 & 1.491 & 15,7 & 3.038 & 16,4 & 2.171 \\
\hline & São Paulo & 4,4 & 1.675 & 6,2 & 2.225 & 23,0 & 1.611 & 3,9 & 2.178 & 5,2 & 4.510 & 11,2 & 3.407 \\
\hline & Sul & 20,1 & 1.331 & 18,2 & 2.055 & 18,4 & 1.972 & 16,9 & 2.372 & 17,7 & 3.379 & 18,7 & 2.779 \\
\hline \multirow{2}{*}{$\begin{array}{l}\text { Filho(s) } \\
\text { jovem(s) }\end{array}$} & Sem & 71,9 & 845 & 49,2 & 1.326 & 72,6 & 1.346 & 77,1 & 1.419 & 53,2 & 2.523 & 74,6 & 2.040 \\
\hline & Com & 28,1 & 932 & 50,8 & 1.343 & 27,4 & 1.578 & 22,9 & 1.293 & 46,8 & 2.165 & 25,4 & 2.387 \\
\hline \multirow{2}{*}{$\begin{array}{l}\text { Filho(s) } \\
\text { adulto(s) }\end{array}$} & Sem & 87,1 & 792 & 79,2 & 1.177 & 91,9 & 1.322 & 87,2 & 1.258 & 76,9 & 2.044 & 87,8 & 1.959 \\
\hline & Com & 12,9 & 1.360 & 20,8 & 1.833 & 8,1 & 2.361 & 12,8 & 2.028 & 23,1 & 3.100 & 12,2 & 3.293 \\
\hline \multirow{2}{*}{$\begin{array}{l}\text { Cônjuge em } \\
\text { idade ativa }\end{array}$} & Sem & 32,0 & 1.152 & 17,8 & 1.678 & 26,9 & 1.368 & 38,1 & 1.773 & 20,1 & 2.862 & 31,8 & 2.295 \\
\hline & Com & 68,0 & 799 & 82,2 & 1.265 & 73,1 & 1.444 & 61,9 & 1.228 & 79,9 & 2.194 & 68,2 & 2.108 \\
\hline \multirow{2}{*}{ Aposentado(s) } & Sem & 69,8 & 727 & 76,5 & 1.169 & 87,5 & 1.346 & 64,8 & 1.046 & 73,8 & 1.984 & 83,6 & 1.931 \\
\hline & Com & 30,2 & 1.287 & 23,5 & 1.868 & 12,5 & 1.983 & 35,2 & 2.115 & 26,2 & 3.265 & 16,4 & 3.289 \\
\hline \multirow{6}{*}{ Faixa etária } & menos de 20 anos & 0,8 & 737 & 0,3 & 1.136 & 1,3 & 1.281 & 0,5 & 1.122 & 0,1 & 1.970 & 1,2 & 1.864 \\
\hline & de 20 a 29 anos & 14,1 & 842 & 9,9 & 1.433 & 19,7 & 1.423 & 9,1 & 1.230 & 7,3 & 2.410 & 15,2 & 2.014 \\
\hline & de 30 a 39 anos & 21,5 & 876 & 21,2 & 1.307 & 30,6 & 1.469 & 17,7 & 1.304 & 19,2 & 2.341 & 27,4 & 2.131 \\
\hline & de 40 a 49 anos & 19,2 & 937 & 27,7 & 1.468 & 24,3 & 1.537 & 20,4 & 1.302 & 27,2 & 2.353 & 24,8 & 2.332 \\
\hline & de 50 a 59 anos & 18,6 & 1.058 & 23,3 & 1.624 & 13,1 & 1.858 & 22,3 & 1.499 & 25,6 & 2.528 & 17,3 & 2.610 \\
\hline & 60 anos ou mais & 25,8 & 1.323 & 17,6 & 1.957 & 10,9 & 1.973 & 30,0 & 2.107 & 20,6 & 3.271 & 14,1 & 3.144 \\
\hline \multirow{2}{*}{ Sexo } & Masculino & 89,7 & 891 & 91,5 & 1.356 & 83,0 & 1.442 & 83,7 & 1.391 & 82,0 & 2.401 & 73,7 & 2.194 \\
\hline & Feminino & 10,3 & 865 & 8,5 & 1.315 & 17,0 & 1.414 & 16,3 & 1.362 & 18,0 & 2.248 & 26,3 & 2.114 \\
\hline \multirow{2}{*}{ Cor ou raça } & Preta, parda ou indígena & 56,5 & 670 & 54,3 & 1.068 & 48,3 & 1.148 & 63,9 & 1.113 & 62,1 & 1.957 & 58,6 & 1.789 \\
\hline & Branca ou amarela & 43,5 & 1.180 & 45,7 & 1.700 & 51,7 & 1.710 & 36,1 & 1.878 & 37,9 & 2.922 & 41,5 & 2.673 \\
\hline \multirow{4}{*}{ Escolaridade } & Sem escolaridade & 44,8 & 680 & 36,0 & 1.033 & 22,0 & 1.084 & 33,8 & 1.166 & 23,5 & 1.912 & 14,1 & 1.727 \\
\hline & $1^{\circ}$ incompleto & 43,6 & 913 & 47,2 & 1.253 & 40,4 & 1.254 & 41,3 & 1.375 & 41,2 & 2.130 & 27,9 & 1.856 \\
\hline & $1^{\mathrm{o}}$ completo ou $2^{\mathrm{o}}$ incomp. & 9,8 & 1.097 & 12,4 & 1.485 & 24,2 & 1.484 & 17,6 & 1.456 & 21,6 & 2.147 & 26,9 & 2.046 \\
\hline & $2^{\circ}$ completo ou mais & 1,9 & 2.264 & 4,5 & 2.451 & 13,4 & 2.733 & 7,3 & 1.860 & 13,7 & 3.112 & 31,1 & 2.841 \\
\hline
\end{tabular}

* Valores deflacionados para outubro de 2013, segundo a metodologia de Corseiul e Foguel (2002).

Fonte: PNAD/IBGE. Exclusive os residentes do Norte (exceto TO). Exclusive os domicílios com nenhum membro ocupado. 
região Sul (19\%) e, sobretudo, no estado de São Paulo (11\%).

Mulheres na posição de referência no domicílio ainda representam a minoria dos domicílios rurais, apesar do crescimento elevado no período. As famílias Não Agrícolas apresentam a maior participação de chefia feminina $(26,3 \%$ do total de domicílios Não Agrícolas em 2013, contra 18\% das famílias Pluriativas e 16,3\% das famílias Agrícolas). Por sua vez, famílias chefiadas por pessoas da cor branca ou amarela, que possuem rendimentos médios substancialmente superiores e são mais representativas entre as famílias Não Agrícolas, reduziram sensivelmente suas participações entre todos os tipos de domicílios rurais.

Finalmente, a escolaridade da pessoa responsável também possui uma forte relação com a renda domiciliar e com o tipo de atividade da família. Como esperado, as famílias Agrícolas apresentam os menores níveis de escolaridade, com mais de um terço dessas lideradas por uma pessoa sem qualquer escolaridade. As famílias Pluriativas se caracterizam pela participação de pessoas responsáveis com $1^{\mathrm{o}}$ grau incompleto (41\% em 2013) e as famílias Não Agrícolas diferenciavam-se pela concentração dos responsáveis com $2^{\circ}$ grau completo ou mais $(31 \%)$, que estão associados aos maiores rendimentos domiciliares. Deve-se também destacar o fato de o percentual de famílias chefiadas por pessoas com pelo menos o $1^{\mathrm{o}}$ grau de escolaridade ter crescido substancialmente entre 2001 e 2013, sobretudo entre as famílias Pluriativas (18 pontos percentuais) e Não Agrícolas (20 pontos percentuais).

\subsection{Condicionantes da Pluriatividade e da condição não agrícola}

Apesar de as análises anteriores fornecerem importantes elementos para compreender os padrões de associação entre as variáveis de interesse, não estabelecem relações de causa e efeito entre as características socioeconômicas e a condição de atividade das famílias. Não permitem, por exemplo, saber se a concentração de jovens em famílias Pluriativas é devida às características socioeconômicas dessas famílias, como maior escolaridade ou região de residência, ou devida à maior propensão desses em desempenharem atividades não agrícolas.

Para cumprir com este objetivo, foi ajustado um modelo de regressão logística multinomial definido pela equação (1). O modelo se ajustou significativamente ao nível de $0,01 \%$, ou seja, pelo menos um dos coeficientes do modelo é estatisticamente diferente de zero. A Tabela 2 apresenta as estimativas de máxima verossimilhança para os coeficientes dos modelos de regressão logística multinomial (ou seja, as estimativas para $\theta$ e $\delta$ na equação 1). Como o tipo familiar Agrícola é usado como referência, as estimativas refletem o impacto de cada característica socioeconômica sobre a probabilidade de a família pertencer ao tipo Pluriativa ou Não Agrícola quando comparada à probabilidade de pertencer ao tipo Agrícola (odds).

Dentre as variáveis investigadas, destaque pode ser dado ao tipo de localidade. Residir em áreas muito próximas das áreas urbanas (áreas rurais de extensão urbana) aumentam, sobretudo, as chances de uma família pertencer ao grupo de Não Agrícola em relação ao Agrícola. A propensão de uma família ser Pluriativa também é substancialmente elevada neste tipo de localidade. Em razão da proximidade e, consequentemente, pelo fácil acesso as áreas urbanas, as atividades não agrícolas dessas famílias seriam, provavelmente, estritamente urbanas, ou seja, exercidas fora do perímetro rural. Residir em áreas rurais aglomeradas, isoladas e povoadas também se traduz em uma propensão positivamente elevada da família pertencer à categoria Pluriativa e, sobretudo, Não Agrícola. Não podemos afirmar que estas áreas são próximas ou proporcionem acesso fácil às atividades das áreas urbanas. No entanto, podemos afirmar que apresentam uma estrutura mínima de vias públicas (como estradas e ruas) e comunicação, assim como serviços básicos (educação, saúde ou instituição religiosa) no próprio meio rural. Ou seja, as atividades não agrícolas dessas famílias podem também estar ligadas ao dinamismo do próprio espaço rural em que residem. 
Residir no estado de São Paulo aumenta substancialmente a propensão de a família pertencer à categoria Não Agrícola e, em menor escala, Pluriativa. Os domicílios rurais paulistas são predominantemente Não Agrícolas (49\% do total dos domicílios do estado em 2013) - isso muito provavelmente se deve ao maior dinamismo das redes urbanas no interior desse estado (NASCIMENTO e CARDOZO, 2007; KAGEYAMA, 2008). Além disso, a pluriatividade também responde por parcela significativa no estado (16\%). A região CentroOeste apresenta as segundas maiores propensões de as famílias pertencerem ao tipo Pluriativa ou Não Agrícola. Apesar do resultado, é importante frisar que esta região, em termos absolutos, não detém parcela relevante do total de famílias brasileiras rurais. Como todos os coeficientes associados às regiões são positivos, a propensão a desempenhar uma atividade não agrícola seria menor na região Nordeste (referência de análise), independente dos demais fatores de controle.

Famílias Empregadoras são mais propensas a pertencerem à categoria Pluriativa ou Não Agrícola, seguida pelas famílias Conta-própria e, por último, pelas famílias Empregadas. A baixa participação relativa de empregadores e conta-própria no tipo familiar Agrícola pode, por um lado, estar associada às dificuldades econômicas enfrentadas pelos pequenos e médios produtores que têm se traduzido na queda da participação relativa de empregadores entre o total dos ocupados agrícolas (BUAINAIN et al., 2014). Por outro lado, pode estar associada à própria ramificação da atividade agrícola familiar - como por exemplo, famílias que contam com a presença de um empregador podem gerar maiores oportunidades de ocupações aos demais membros familiares em atividades fora da agricultura, ampliando consequentemente a propensão dessas famílias Empregadoras a pertencer à categoria Pluriativa.

Como esperado, a renda agrícola é componente fundamental para explicar a propensão à atividade não agrícola. Para cada aumento percentual na renda (domiciliar per capita) proveniente do trabalho em atividades agrícolas, observa-se, em média, queda de $0,24 \%$ nas chan- ces de uma família ser Pluriativa em comparação a ser Agrícola. A relação para a propensão a ser Não Agrícola é ainda mais intensa. Em outras palavras, a pluriatividade e a atividade não agrícola surgem como importantes formas de complementação da renda das famílias em que o rendimento da agricultura é mais baixo. Logo, espera-se que famílias com rendimentos agrícolas elevados não tenderiam a buscar por ocupações fora da agricultura, consideradas as demais variáveis de controle constante.

Famílias com filhos jovens são mais propensas à pluriatividade (na comparação com famílias que não contam com a presença de filhos jovens). Esse resultado pode estar associado tanto à busca por atividades fora da agricultura da população rural mais jovem (frente às condições precárias da atividade agrícola ou à atratividade das atividades urbanas não agrícolas), quanto ao fato de que famílias maiores (que contam com a presença de filhos dispostos ao trabalho fora do domicílio) têm naturalmente maiores chances de diversificarem a fonte de renda domiciliar. Neste sentido, as estimativas revelam que famílias com filhos adultos apresentam propensões ainda maiores de pertencerem às categorias Não Agrícola e, sobretudo, Pluriativa, resultado que revela a disposição dos integrantes que se encontram em estágios mais consolidados do ciclo de vida familiar em buscar e ocupar atividades fora da agricultura. Como analisado por Maia (2014), é na faixa etária dos 20 a 29 anos que a transição da atividade agrícola para a não agrícola é mais intensa, sobretudo para as mulheres e pessoas com maior escolaridade que buscam melhores oportunidades de emprego nos centros urbanos.

Famílias com cônjuges em idade ativa têm $119 \%$ mais chances de serem pluriativas do que agrícolas (na comparação com famílias que não têm cônjuges ou têm cônjuge em idade inativa). Essa elevada propensão pode estar relacionada a uma estratégia familiar de fuga à pobreza. Frente à insuficiência de renda gerada na agricultura, as mulheres (na posição de cônjuge) buscariam por atividades não agrícolas como forma de complementação à renda domiciliar. 
Tabela 2. Estimativas de máxima verossimilhança para a propensão dos domicílios rurais pertencerem ao grupo de pluriativos e não agrícolas. Brasil, 2001 a 2013

\begin{tabular}{|c|c|c|c|c|c|c|}
\hline \multirow{2}{*}{ Variáveis } & \multicolumn{3}{|c|}{ Famílias Pluriativas } & \multicolumn{3}{|c|}{ Famílias Não Agrícolas } \\
\hline & Estimativas & Odds ratio & Valor $p$ & Estimativas & Odds ratio & Valor $p$ \\
\hline Variação anual $(t)$ & 0,023 & 1,023 & $<0,001$ & 0,005 & 1,005 & 0,364 \\
\hline 2000 (2001 a 2009) & - & 1,000 & - & - & 1,000 & - \\
\hline $2010(2011,2012$ e 2013$)$ & $-0,101$ & 0,904 & $<0,001$ & $-0,219$ & 0,803 & $<0,001$ \\
\hline Log da renda per capita agrícola & $-0,270$ & 0,763 & $<0,001$ & $-31,450$ & 0,043 & $<0,001$ \\
\hline Famílias conta-própria & - & 1,000 & - & - & 1,000 & - \\
\hline Família empregadora & 0,507 & 1,660 & $<0,001$ & 0,487 & 1,627 & $<0,001$ \\
\hline Família empregada & $-0,480$ & 0,619 & $<0,001$ & $-13,180$ & 0,268 & $<0,001$ \\
\hline Áreas isoladas e não povoadas & - & - & - & - & 1,000 & - \\
\hline Extensão urbana & 11,195 & 3,063 & $<0,001$ & 31,219 & 22,688 & $<0,001$ \\
\hline Aglomerado, isolado e povoado & 0,575 & 1,778 & $<0,001$ & 13,201 & 3,744 & $<0,001$ \\
\hline NE (mais TO) & - & 1,000 & - & - & 1,000 & - \\
\hline $\mathrm{CO}$ & 0,549 & 1,731 & $<0,001$ & 11,171 & 3,056 & $<0,001$ \\
\hline SE (exceto SP) & 0,329 & 1,389 & $<0,001$ & 0,898 & 2,454 & $<0,001$ \\
\hline $\mathrm{SP}$ & 0,785 & 2,192 & $<0,001$ & 25,651 & 13,002 & $<0,001$ \\
\hline S & 0,233 & 1,263 & $<0,001$ & 0,900 & 2,459 & $<0,001$ \\
\hline Tem filho jovem & 0,873 & 2,394 & $<0,001$ & 0,364 & 1,439 & $<0,001$ \\
\hline Tem filho adulto & 13,175 & 3,734 & $<0,001$ & 10,586 & 2,882 & $<0,001$ \\
\hline Tem Cônjuge Idade Ativa & 0,784 & 2,190 & $<0,001$ & 0,116 & 1,123 & $<0,001$ \\
\hline Aposentado no domicílio & $-0,281$ & 0,755 & $<0,001$ & $-10,705$ & 0,343 & $<0,001$ \\
\hline menos de 20 anos & - & 1,000 & - & - & 1,000 & - \\
\hline de 20 a 29 anos & 0,357 & 1,429 & 0,009 & $-0,225$ & 0,798 & 0,167 \\
\hline de 30 a 39 anos & 0,563 & 1,757 & $<0,001$ & $-0,353$ & 0,703 & 0,029 \\
\hline de 40 a 49 anos & 0,523 & 1,688 & $<0,001$ & $-0,669$ & 0,512 & $<0,001$ \\
\hline de 50 a 59 anos & 0,340 & 1,405 & 0,013 & $-10,885$ & 0,337 & $<0,001$ \\
\hline 60 anos ou mais & 0,152 & 1,164 & 0,272 & $-15,950$ & 0,203 & $<0,001$ \\
\hline Homem & - & 1,000 & - & - & 1,000 & - \\
\hline Mulher & 0,063 & 1,065 & 0,019 & 0,025 & 1,026 & 0,440 \\
\hline Preta, parda ou indígena & - & 1,000 & - & - & 1,000 & - \\
\hline Branca ou amarela & 0,025 & 1,026 & 0,144 & $-0,022$ & 0,978 & 0,392 \\
\hline Sem escolaridade & - & 1,000 & - & - & 1,000 & - \\
\hline $1^{\mathrm{o}}$ incompleto & 0,342 & 1,407 & $<0,001$ & 0,432 & 1,541 & $<0,001$ \\
\hline $1^{\mathrm{o}}$ completo $2^{\mathrm{o}}$ incompleto & 0,667 & 1,949 & $<0,001$ & 11,706 & 3,224 & $<0,001$ \\
\hline $2^{\circ}$ completo ou mais & 11,229 & 3,074 & $<0,001$ & 20,602 & 7,848 & $<0,001$ \\
\hline
\end{tabular}

Fonte: Elaboração dos autores com base nos dados da PNAD/IBGE. Exclusive as famílias sem nenhum membro ocupado. Exclusive os residentes do Norte (exceto TO).

A existência de um aposentado (ou mais) na família aumenta significativamente a propensão à atividade agrícola. Em outras palavras, famílias que contam com a presença de pelo menos um aposentado apresentam propensões negativas de pertencerem à categoria Pluriativa ou Não Agrícola. Isso pode ser analisado por dois fatores determinantes: i) essas famílias se encontram em estágios mais avançados do ciclo de vida familiar e, portanto, contam com menor presença de força de trabalho ativo e pessoas dispostas a se aventurarem em atividades fora da agricultura; ii) as famílias apresentam renda domiciliar garantida pela aposentadoria rural e, portanto, apresentam menor necessidade de complementar a renda domiciliar com atividades fora da agricultura (ou seja, a aposentadoria representaria um fator favorável de permanência no rural agrícola). 
Neste sentido, famílias chefiadas por pessoas com 60 anos ou mais apresentam as menores propensões a pertencerem à categoria Pluriativa ou Não Agrícola (na comparação com famílias chefiadas por pessoas com menos de 20 anos), mesmo após os demais fatores serem controlados. A faixa etária entre 30 e 39 anos de idade apresenta a maior propensão à pluriatividade. Já as faixas etárias mais jovens são associadas à maiores chances de pertencerem à categoria Não Agrícola, revelando a disposição (ou a necessidade) dos jovens rurais em se inserirem em atividades fora da agricultura. Assim, o estágio do ciclo de vida familiar seria importante determinante do tipo de atividade econômica da família (dependendo da oferta de mão de obra em idade ativa no domicílio). No geral, as atividades agrícolas estão relacionadas com domicílios que se encontram em estágios mais avançados do ciclo de vida familiar.

Em relação às estimativas que poderiam indicar alguma forma de segregação na inserção ocupacional (que diferenciam cor/raça e sexo da pessoa de referência), os resultados não se mostraram, em grande parte, significativos. A exceção é a maior propensão de as famílias lideradas por mulheres serem Pluriativas em comparação a serem Agrícolas (chances 6\% superiores às das famílias lideradas por homens). Resultado este que revelaria, provavelmente, a elevada participação de mulheres rurais em atividades não agrícolas urbanas, como o serviço doméstico remunerado.

A escolaridade da pessoa de referência é outra característica que condiciona fortemente o tipo de atividade exercida pela família. Quanto maior essa escolaridade, maior será a propensão de a família ser Não Agrícola e Pluriativa, sobretudo aquelas chefiadas por pessoas com $2^{\circ}$ grau completo. Em outras palavras, responsáveis familiares com diplomas de segundo grau teriam probabilidades de encontrarem uma ocupação não agrícola, usualmente melhor remuneradas e com maior exigência de qualificação.

Consideradas as características familiares constantes, aumentaram as chances de as famílias rurais serem Pluriativas (2,3\% ao ano). Esse crescimento poderia estar associado a inúmeros fatores não controlados pelo modelo. Por exemplo, melhorias de infraestrutura (construção de ruas e melhorias no transporte público) que possibilitem maior acesso às áreas urbanas e, consequentemente, tenderiam a elevar as chances de um residente rural exercer atividades não agrícolas no urbano. Ou à maior atratividade das ocupações não agrícolas. Não há, entretanto, mudanças significativas na propensão de as famílias serem não agrícolas no tempo. Como aumentou o percentual de famílias não agrícolas no período (Figura 1), os resultados sugerem que esta variação seria devida, sobretudo, às mudanças das características familiares controladas pelo modelo, como o aumento da escolaridade.

Por fim, vale destacar que mudanças de classificação das áreas legalmente rurais (decretadas pelos órgãos municipais e inseridas nas pesquisas das PNAD após cada ano censitário) foram controladas no modelo pela inclusão da variável binária de década. Como esperado, os anos da década de 2010 apresentam propensões negativas à categoria Não Agrícola e Pluriativa (desconsiderando os impactos das demais variáveis), em razão da incorporação de áreas rurais próximas às áreas urbanas ao perímetro urbano legal de cada município (alteração que acaba excluindo, proporcionalmente, mais famílias não agrícolas e pluriativas das áreas rurais do que famílias agrícolas).

\subsection{Diferenciais de renda}

Para avaliar em que medida a atividade não agrícola contribui para aumentar a renda do domicílio rural, ajustou-se um modelo de regressão linear múltipla para o logaritmo da renda domiciliar total (equação 2). $\mathrm{O}$ ajuste por Mínimos Quadrados Ordinários mostrou-se significativo a $0,01 \%$, com coeficiente de determinação igual a $44 \%$. Em função do elevado número de observações da amostra, todas as estimativas dos coeficientes mostraram-se significativas a 3\% (Tabela 3). 
Tabela 3. Estimativas de Mínimos Quadrados Ordinários para o logaritmo da renda total domiciliar. Brasil, 2001 a 2013

\begin{tabular}{|c|c|c|c|c|}
\hline Variável & Estimativa & Erro Padrão & $t$ & Valor $p$ \\
\hline Agrícola & - & - & - & - \\
\hline Pluriativa & 0,130 & 0,011 & 12,31 & $<0,001$ \\
\hline Não agrícola & 0,324 & 0,010 & 31,96 & $<0,001$ \\
\hline Variação anual $(t)$ & 0,028 & 0,001 & 28,09 & $<0,001$ \\
\hline Agrícola $\mathrm{x} t$ & - & - & - & - \\
\hline Pluriativa $\mathrm{x} t$ & 0,014 & 0,001 & 9,76 & $<0,001$ \\
\hline Não Agrícola x t & 0,006 & 0,001 & 4,42 & $<0,001$ \\
\hline 2000 (2001 a 2009) & - & - & - & - \\
\hline 2010 (2011 a 2013) & 0,026 & 0,008 & 3,28 & 0,001 \\
\hline Famílias conta-própria & - & - & - & - \\
\hline Família empregadora & 0,714 & 0,011 & 67,18 & $<0,001$ \\
\hline Família empregada & $-0,121$ & 0,004 & $-27,67$ & $<0,001$ \\
\hline Áreas isoladas e não povoadas & - & - & - & - \\
\hline Extensão urbana & 0,052 & 0,013 & 4,14 & $<0,001$ \\
\hline Aglomerado, isolado e povoado & $-0,016$ & 0,007 & $-2,30$ & 0,022 \\
\hline NE (mais TO) & - & - & - & - \\
\hline $\mathrm{CO}$ & 0,619 & 0,008 & 73,95 & $<0,001$ \\
\hline SE (exceto SP) & 0,397 & 0,006 & 65,03 & $<0,001$ \\
\hline SP & 0,600 & 0,009 & 68,08 & $<0,001$ \\
\hline S & 0,569 & 0,006 & 88,52 & $<0,001$ \\
\hline Tem filho jovem & 0,041 & 0,005 & 7,90 & $<0,001$ \\
\hline Tem filho adulto & 0,050 & 0,007 & 7,09 & $<0,001$ \\
\hline Tem Cônjuge Idade Ativa & 0,094 & 0,006 & 16,00 & $<0,001$ \\
\hline Aposentado no domicílio & 0,489 & 0,007 & 69,22 & $<0,001$ \\
\hline Número de pessoas com renda & 0,383 & 0,003 & 142,43 & $<0,001$ \\
\hline menos de 20 anos & - & - & - & - \\
\hline de 20 a 29 anos & 0,154 & 0,026 & 5,85 & $<0,001$ \\
\hline de 30 a 39 anos & 0,280 & 0,026 & 10,70 & $<0,001$ \\
\hline de 40 a 49 anos & 0,288 & 0,026 & 10,96 & $<0,001$ \\
\hline de 50 a 59 anos & 0,295 & 0,027 & 11,12 & $<0,001$ \\
\hline 60 anos ou mais & 0,457 & 0,027 & 16,89 & $<0,001$ \\
\hline Homem & - & - & - & - \\
\hline Mulher & $-0,029$ & 0,007 & $-4,39$ & $<0,001$ \\
\hline Preta, parda ou indígena & - & - & - & - \\
\hline Branca ou amarela & 0,102 & 0,005 & 21,87 & $<0,001$ \\
\hline Sem escolaridade & - & - & - & - \\
\hline $1^{\mathrm{o}}$ incompleto & 0,126 & 0,005 & 24,42 & $<0,001$ \\
\hline $1^{\mathrm{o}}$ completo $2^{\mathrm{o}}$ incompleto & 0,303 & 0,007 & 43,49 & $<0,001$ \\
\hline $2^{\mathrm{o}}$ completo ou mais & 0,619 & 0,009 & 71,48 & $<0,001$ \\
\hline
\end{tabular}

Fonte: Elaboração dos autores com base nos dados da PNAD/IBGE. Exclusive as famílias sem nenhum membro ocupado. Exclusive os residentes do Norte (exceto TO).

Os coeficientes associados às variáveis Pluriativa e Não Agrícola indicam o diferencial de renda em relação às famílias Agrícolas em 2001. As estimativas revelam que as famílias do tipo Não Agrícola apresentavam os maiores níveis de renda domiciliar média (38\% superior ao das famílias agrícolas, $\left.e^{0,324}-1=0,383\right)$, seguidas pelas famílias pluriativas ( $14 \%$ superior ao das famílias agrícolas). Em outras palavras, independente das características socioeconômicas da família, desempenhar uma atividade não agrícola significava importante estratégia para aumentar a renda domiciliar. 
Os coeficientes positivos para as variáveis de interação do tipo familiar com o tempo $(t)$ indicam, mantendo-se constantes os demais regressores, que as famílias Pluriativas apresentaram valorização $1,4 \%$ ao ano superior à valorização da renda das Agrícolas, e as famílias Não Agrícolas, $0,6 \%$ superior. Logo, pode-se inferir que a renda das Pluriativas cresceu em ritmo mais acelerado na comparação com as demais famílias com as mesmas características, ou seja, após controlados os efeitos das características socioeconômicas das famílias. Ou seja: os diferenciais de renda entre as famílias se acentuaram durante o período. Cabe frisar que, apesar desse resultado, as famílias Agrícolas também apresentaram valorização substancial da renda. Interpretando o coeficiente de variação anual, destaca-se que as famílias agrícolas apresentam um aumento total da renda domiciliar de 2,8\% ao ano entre 2001 e 2013. Como exemplo de tal valorização, podemos inferir que a renda de uma família Agrícola em 2013 atingiu o nível de renda de uma família Não Agrícola observado em 2001 (mantidas as características constantes).

O coeficiente associado aos anos 2010 controla as mudanças na delimitação do espaço rural e indica que esta foi responsável por uma variação positiva de $2,6 \%$ na renda domiciliar rural total. Adicionalmente, as estimativas dos coeficientes associados aos demais regressores do modelo permitem outras importantes considerações sobre os diferenciais de renda rural. Por exemplo, residir em áreas rurais de extensão urbana oferecem melhores oportunidades de obtenção da renda, independente das demais características familiares (5\% superior ao das áreas isoladas e não povoadas). Como esperado, as disparidades regionais são também expressivas. Famílias rurais da região Centro-Oeste, Sul e estado de São Paulo apresentam renda domiciliar média cerca de $80 \%$ superior ao das residentes na região Nordeste.

Famílias constituídas exclusivamente por empregados tinham renda domiciliar média substancialmente inferior à dos demais tipos familiares (cerca de 11\% inferior ao das famílias de contas-próprias, que, por sua vez, tinham renda inferior ao das famílias de empregadores).
As famílias que contam com a presença de filhos jovens ou adultos e que contam com a presença de cônjuges em idade ativa apresentam, em média, renda domiciliar superior à das demais famílias, mesmo após controlado o número de pessoas com renda positiva na família. Por outro lado, os retornos são substancialmente maiores quando a família conta com a presença de uma pessoa aposentada (renda domiciliar média 63\% superior à das famílias sem aposentado com as mesmas características).

A idade da pessoa responsável é outro importante determinante da renda domiciliar, com vantagens àqueles com maior experiência. Analogamente, a escolaridade desta pessoa de referência também interfere de maneira substancial na renda das famílias rurais, sobretudo para aqueles com $1^{\mathrm{o}}$ ou $2^{\mathrm{o}}$ grau completo. O rendimento médio das famílias comandadas por mulheres era marginalmente inferior ao das famílias comandas por homens (3\% inferior). Os diferenciais de renda relacionados com a cor ou raça da pessoa de referência eram ainda mais significativos, $11 \%$ superior para as famílias lideradas por pessoas da cor branca ou amarela.

\section{Considerações finais}

Apesar das sensíveis melhoras no emprego e renda agrícolas nos anos 2000, manteve-se o ritmo histórico de redução das famílias com atividade exclusivamente agrícola no Brasil. A mudança mais expressiva foi o crescimento de mais de meio milhão de domicílios rurais com ocupados exclusivamente em atividades não agrícolas. Mas também foi expressivo o crescimento de 170 mil domicílios pluriativos. Essa estratégia das famílias rurais encontra, em grande medida, respaldo nos retornos à renda domiciliar, que é substancialmente superior para as famílias com pelo menos um integrante em atividade não agrícola.

São vários os fatores que definem as chances de a família ser Pluriativa ou Não Agrícola, entre os quais podem ser destacados: i) localidade rural (especialmente se residem perto das 
áreas urbanas); ii) região de residência; iii) se tem filho em idade adulta residindo no domicílio; iv) escolaridade da pessoa responsável. Em relação à localidade de residência, famílias que residem em áreas rurais mais isoladas, sem estrutura mínima de serviços, não têm muitas oportunidades para se inserirem no mercado de trabalho não agrícola, seja pelo baixo dinamismo da localidade onde residem, seja pelo difícil acesso às áreas urbanas, ou áreas que ofereçam maiores oportunidade de trabalho não agrícola.

A propensão à pluriatividade e à atividade exclusivamente não agrícola é maior, sobretudo, no estado de São Paulo, o que refletiria (i) a maior interação entre as áreas rurais e urbanas paulistas (o que facilita o acesso às ocupações estritamente urbanas) e (ii) presença de atividades agrícolas dinâmicas que acabam ramificando maiores oportunidades de trabalho fora da agricultura no próprio meio rural paulista. Apesar de as análises não destacarem a propensão à pluriatividade ou à atividade não agrícola da região Sul, deve-se destacar que esta costuma estar associada a uma ramificação da agricultura familiar de pequeno e médio porte na região, ou seja, exercida dentro dos estabelecimentos familiares. Acabam, assim, sendo subestimadas pelas pesquisas domiciliares, como a PNAD, cuja categorização do trabalho da pessoa se baseia pelo tipo de atividade econômica principal do estabelecimento em que a pessoa exerceu o trabalho. Por sua vez, a região Nordeste concentra a maior parcela das famílias rurais do País e apresenta a maior propensão à atividade exclusivamente agrícola, o que estaria associado ao baixo dinamismo da atividade não agrícola frente à agrícola.

A presença de um filho em idade adulta no domicílio é outro importante determinante da atividade domiciliar pluriativa ou não agrícola. Isso reflete a busca por melhores oportunidades de trabalho (fora da atividade agrícola) daqueles integrantes. Por outro lado, a presença de um aposentado na família é o principal determinante do exercício da atividade exclusivamente agrícola no domicílio rural. A expansão dos benefícios da aposentadoria rural e a expressiva valorização do salário mínimo no período estariam fornecendo importante retaguarda às famílias que praticam a atividade agrícola. Assim, o rendimento relativamente elevado deste benefício seria suficiente para que muitos integrantes de domicílios rurais não sejam forçados à procura por atividades não agrícolas para complementação da renda domiciliar.

Em relação à dinâmica no tempo, concluiu-se que o elevado aumento da participação das famílias Não Agrícolas no total dos domicílios rurais é explicado, sobretudo, por mudanças internas às famílias, como maior escolaridade e mudanças na estrutura etária. Por outro lado, o aumento da propensão à pluriatividade das famílias rurais foi significativamente influenciado por mudanças exógenas às características investigadas no estudo. Por exemplo, mudanças no estágio de desenvolvimento da atividade econômica nos centros urbanos e, consequentemente, maior atração da mão de obra rural, ou mesmo maior interação entre as atividades agrícolas e não agrícolas das famílias rurais, além do número maior de políticas públicas voltadas para as áreas rurais (particularmente para a agricultura familiar) nos anos 2000.

As famílias Não Agrícolas e, posteriormente, Pluriativas apresentam rendimentos domiciliares médios superiores ao das famílias Agrícolas com características socioeconômicas semelhantes. Em outras palavras, o exercício da atividade não agrícola seria uma boa estratégia para aumento da renda no domicílio rural. Ademais, as famílias Pluriativas tiveram a maior valorização da renda média total domiciliar no período, seguida pelas famílias Não Agrícolas e Agrícolas. Como resultado, os expressivos diferenciais de renda domiciliar entre as famílias rurais se intensificaram no período, revelando maior dificuldade das famílias que dependem exclusivamente de atividades agrícolas. Esses sugerem a potencialidade das atividades não agrícolas na geração de renda rural, frente às políticas de desenvolvimento da atividade agrícola familiar (ver, por exemplo, SCHNEIDER, 2009).

De maneira geral, as análises permitem importantes considerações sobre a dinâmica das atividades não agrícolas no meio rural brasileiro. 
Por exemplo, o aumento da escolaridade da população rural tende a aumentar a inserção dessa população em atividades não agrícolas. Por sua vez, o envelhecimento das famílias rurais tende a diminuir as chances de pelo menos um membro ocupado em alguma atividade não agrícola, dependendo, sobretudo, de políticas que garantam a continuidade dos benefícios das aposentadorias rurais. Mas, acima de tudo, também destaca a relevância da dinâmica do mercado de trabalho agrícola, uma vez que a renda agrícola está inversamente relacionada à propensão à atividade não agrícola no domicílio rural.

Deve-se também destacar alguns pontos não abordados nessas análises. A atividade secundária do trabalhador não foi considerada, ou seja, se um mesmo trabalhador dividia o tempo de trabalho entre duas atividades (uma agrícola e outra não agrícola de caráter complementar) - os chamados trabalhadores part time. Tampouco foram analisados os diferenciais qualitativos dentre as atividades não agrícolas, embora esses reflitam no rendimento domiciliar. Outro aspecto relevante diz respeito à abordagem dos determinantes dos diferentes tipos de pluriatividade. Uma análise mais apurada poderia ser realizada com a ampla diversidade de informações dos estabelecimentos agropecuários (familiares e não familiares) disponibilizada pelo Censo Agropecuário de 2006 (ver, por exemplo, ESCHER et al., 2014). A base de dados utilizada no presente estudo - PNAD, que aborda domicílios e não estabelecimentos - não possibilita um estudo com esse nível de profundidade e detalhamento. Por outro lado, a PNAD permite um rico acompanhamento temporal de características importantes da pluriatividade, além de possibilitar a comparação da situação dessas famílias pluriativas com as famílias não agrícolas.

\section{Referências bibliográficas}

ANDERSON, D. e LEISERSON, M. W. Rural Enterprise and Nonfarm Employment. (A World Bank Paper), 87p., 1978.
BALSADI, O. V. Agricultura familiar e pluriatividade no Centro-Oeste. Revista de Política Agrícola, v. XVIII, p. $98-117,2009$.

BELTRÃO, K. I., CAMARANO, A. A. e MELLO, J. L. Mudanças nas condições de vida dos idosos rurais brasileiros: resultados não-esperados dos avanços da seguridade rural. Texto para discussão. Rio de Janeiro, RJ: IPEA, n. 1066, 2005.

BIRD - Banco Internacional De Reconstrução e Desenvolvimento/ Banco Mundial. Relatório sobre o Desenvolvimento Mundial de 2008: Agricultura para o Desenvolvimento. Washington, DC: Banco Mundial, 34p., 2007.

BUAINAIN, A. M. et al. (Eds.). O mundo rural no Brasil do século 21: a formação de um novo padrão agrário e agrícola. Brasília, DF: Embrapa, 2014.

CAMARANO, A. A. e ABRAMOVAY, R. Exxodo rural, envelhecimento e masculinização no Brasil: panorama dos últimos 50 anos. Texto para discussão. Rio de Janeiro, RJ: IPEA, n. 621, 1999.

CAMPANHOLA, C. e SILVA, J. F. G. (Org.). O novo rural brasileiro: uma análise nacional e regional. Jaguariúna, SP: EMBRAPA, 2000.

CARDOSO, J. G. Pluriatividade e politicas públicas na região Nordeste e Sul do Brasil nos anos 1990 e 2000: trajetórias e desafios. Uberlândia, MG: IEUFU, 2013 (Tese de Doutoramento).

CCE - COMISIÓN DE LAS COMUNIDADES EUROPEAS. El Futuro del Mundo Rural, Madrid: Ministerio de Agricultura, Pesca e Alimentación (MAPA), 1998. 149p.

CHAYANOV, A. La organización de la unidad económica campesina. Buenos Aires: Nueva Vision, 1985.

Comissão Nacional de Classificação - CONCLA/IBGE. Disponível em: <http://concla.ibge.gov.br/>. Acesso em: 26 jun. 2015.

CONTERATO, M. A. Dinâmicas regionais do desenvolvimento rural e estilos de agricultura familiar: uma análise a partir do Rio Grande do Sul. Porto Alegre, RS: UFRGS, 2008 (Tese de Doutoramento).

CORSEUIL, C. e FOGUEL, M. Uma sugestão de deflatores para rendas obtidas a partir de algumas pesquisas domiciliares do IBGE. Texto para discussão. Rio de Janeiro, RJ: IPEA, n. 897, 2002.

ESCHER, F. et al. Caracterização da Pluriatividade e dos Plurirrendimentos da Agricultura Brasileira a partir do Censo Agropecuário. Revista de Economia e Sociologia 
Rural-RESR. Piracicaba, SP, v. 52, n. 04, p. 643-668, out./ dez. 2014.

FULLER, A. M. From part-time farming to pluriactivity: a decade of change in rural Europe. Journal of Rural Studies, n. 6, n. 4, p. 361-373, 1990.

HALVORSEN, R.; PALMQUIST, R. The interpretation of Dummy Variables in Semilogarithmic Equations. The American Economic Review, v.70, n.3, p.474-75, jun. 1980.

HILL, B. F. The common agricultural policy: past, present and future. London: Methuen, 1984.

HOFFMANN, R. Como aposentadoria e pensões afetam a educação e o trabalho de jovens do domicílio. Economia e Sociedade, Campinas, v.19, n.1, 2010.

JONASSON, E.; HELFAND, S. How Important are Locational Characteristics for Rural Non-Agricultural Employment? Lessons from Brazil. World Development, 38(5), p.727-41, 2010.

KAGEYAMA, A. A. Desenvolvimento rural: conceitos e aplicações ao caso brasileiro. Rio Grande do Sul: Editora da UFRGS, 2008.

LIMA, J. R. F; PIACENTI, C. A. O papel das rendas nãoagrícolas para a redução da pobreza e concentração na região Sul. Revista Análise Econômica, Porto Alegre, ano 27, n.52, p.51-73, set. 2009.

MAIA, A. O esvaziamento demográfico rural. In: BUAINAIN, A. M. et al. (Ed.). O mundo rural no Brasil do século 21: a formação de um novo padrão agrário e agrícola. Brasília, DF: Embrapa, p. 1013-1031, 2014.

MAIA, A. G.; SAKAMOTO, C. S. A nova configuração do mercado de trabalho agrícola brasileiro. In: BUAINAIN, A. M. et al. (Ed.). O mundo rural no Brasil do século 21: a formação de um novo padrão agrário e agrícola. Brasília, DF: Embrapa, p.591-620, 2014.

MATTEI, L. F. Pluriatividade e desenvolvimento rural no Estado de Santa Catarina. Campinas, SP: Unicamp, 1999 (Tese de Doutoramento).

- A relevância da família como unidade de análise nos estudos sobre pluriatividade. Revista Economia e Sociologia Rural, Rio de Janeiro, v.45, n.04, p.1055-73, out./dez. 2007.

MIRANDA, C.; TIBURCIO, B. (Org.). A nova cara da pobreza rural: desafios para as políticas públicas. Brasília, DF: Série Desenvolvimento Rural Sustentável/ IICA, v.16, 2012.

NASCIMENTO, C. A. Pluriatividade, Pobreza Rural e Serviço Doméstico Remunerado. Revista Economia e Sociologia Rural, v. 42, n. 2, p. 341-64, abr./jun. 2004.
Pluriatividade, Pobreza Rural e Políticas Públicas: uma análise comparada entre Brasil e União Européia. Fortaleza: Banco do Nordeste do Brasil, 2008.

. e CARDOZO, S. A. Redes Urbanas Regionais e a Pluriatividade das Famílias Rurais no Nordeste e no Sul do Brasil, 1992-1999 e 2001-2005. Revista Econômica do Nordeste, v. 38, p. 637-658, 2007.

OECD. Agricultural policy reform and the rural economy in OECD countries. Paris, France: OECD Publications, 1998.

PEREIRA, V. S. N. Atividades agrícolas e não-agrícolas no meio rural do estado do Rio de Janeiro. Campos dos Goytacazes, RJ: Universidade Estadual do Norte Fluminense Darcy Ribeiro, 2010 (Tese de Doutoramento).

PINDYCK, R. S. e RUBINFELD, D. L. Econometria: modelos \& previsões. Rio de Janeiro: Elsevier, 2004.

SACCO DOS ANJOS, F. Agricultura familiar, pluriatividade e desenvolvimento rural no Sul do Brasil. Pelotas: EGUFPEL, 2003.

SCHNEIDER, S. Pluriatividade na Agricultura Familiar. Porto Alegre: Editora da UFRGS. 2003.

. La pluriactividad en el medio rural brasileño: características y perspectivas para la investigación. In: GRAMMONT, H. C. e MARTINEZ VALLE, L. (Orgs.). La pluriactividad en el campo latinoamericano. Quito/ Equador: Ed. Flacso - Serie FORO, v. 1, 2009, p. 132-161.

et al. Pluriatividade e plurirrendimentos nos estabelecimentos agropecuários do Brasil e das regiões Sul e Nordeste: uma análise a partir do Censo Agropecuário 2006. Brasília, DF: IPEA. (Relatório de Pesquisa), 2013.

SILVA, J. F. G. Os desafios das agriculturas brasileiras. In: GASQUES, J. G., VIERIA FILHO, J. E. R. e NAVARRO, $\mathrm{Z}$ (Orgs.). A agricultura brasileira: desempenho, desafios e perspectivas. Brasília, DF: IPEA, v. 1, 2010, p. 157-84.

SOUZA, M. Atividades não-agrícolas e desenvolvimento rural no estado do Paraná. Campinas, SP: Unicamp/ FEAGRI, 2000 (Tese de Doutoramento).

TEIXEIRA, V. L. Novos contornos ocupacionais no meio rural fluminense: um estudo sobre a pluriatividade entre agricultores familiares. Campinas, SP: Unicamp/ IE, 2009 (Tese de Doutoramento).

TOLOSANA, A. O. e PERSIVA, E. M. Estrategia de adaptación de pequenas explotaciones en el marco de la PAC. La agricultura a tiempo parcial en una área de montaña. Revista de Estudios Agro-Sociales, n. 16, p. 99-122, jul./sept. 1992. 
